\title{
The relationship between the personal variables of natural leaders and the cognitive role of natural leadership in the countryside of Qena governorate, Egypt
}

\author{
El-Reedy G. H., Al-Ghazaly R. M. M.* \\ Agricultural Economic Department, Faculty of Agriculture, Minia University, Minia, Egypt
}

\begin{abstract}
The research aims to identify the perceptive role of natural leaders on the importance of the problem of water pollution and work to solve it by disseminating a culture of modern treatments and using nanotechnology applications to solve that problem, and the nature of the variables studied, and the field study was conducted to search in the village of Kalahin Abnud in Qena governorate, Egypt and the population of the village is 334 thousand Nessma. The descriptive analytical method was used, and the mean, iterations, percentages and simple correlation coefficient were used in the statistical analysis. The most important results of the research were as follows:

1. The majority of individuals in the study sample fall into the category of (20-39) years, although they are opinion leaders, and $36.1 \%$ are over sixty years, while $23.3 \%$ of the total sample falls in the age group (40-59 years).

2. The vast majority of the respondents are married.

3. The highest percentage of natural leaders who hold an above average qualification is $26.7 \%$, followed by a higher qualification by $20 \%$, the intermediate qualification $20 \%$, and the preparatory 18 , followed by reading and writing $13.3 \%$, and finally the illiterate $1.3 \%$.

4. That most of the sample population $91.3 \%$ have a high degree of understanding and awareness of the meaning of leadership and service to the people, and that only $2 \%$ who do not have an awareness of the meaning of leadership.

5. About $37.4 \%$ of the total respondents fall in the high category to educate residents about the problems of water pollution.

6. That the degree of the leadership's role in knowing and educating the people about water pollution was $37.4 \%$ of the leaders playing a highly conveyed role in communicating information to the people, and that $52.6 \%$ contribute a moderate degree, only $10 \%$ contribute a low degree and this is a satisfactory result.
\end{abstract}

Keywords: personal variables, cognitive role, natural leadership.

* Corresponding author: Al-Ghazaly R. M. M.,

E-mail address: rasha.elghazaly@yahoo.com 


\title{
العلاقة بين المتغيرات الشخصية للقادة الطبيعيين والدور الإدراكي للقيادة الطبيعية في ريف محافظة قنا بجمهورية الطئية مصر العربية الإنية
}

\author{
جمال حسين الريدي ، رشا محمد محمد الغزالي \\ قسم الاقتصاد الزراعي ، كلية الزراعة ، جامعة المنيا ، المنيا ، جمهورية مصر العربية
}

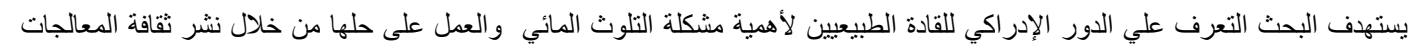

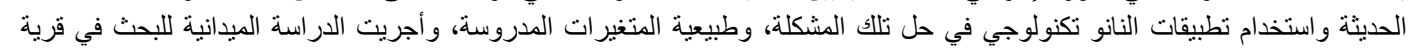

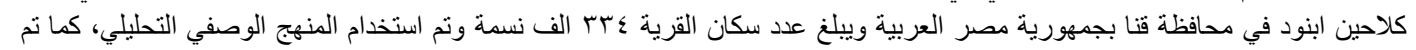

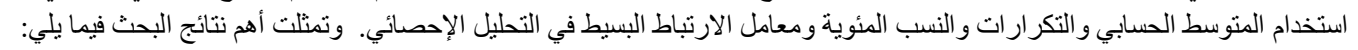

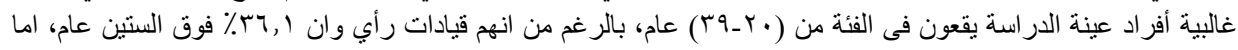

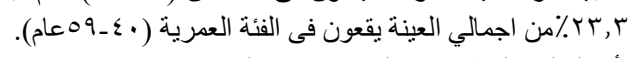

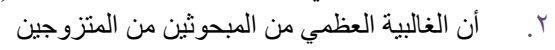

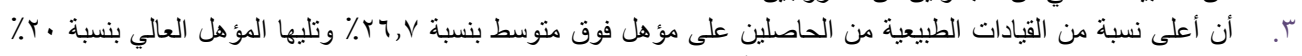

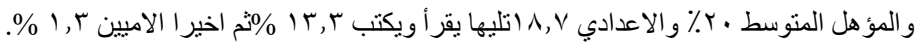

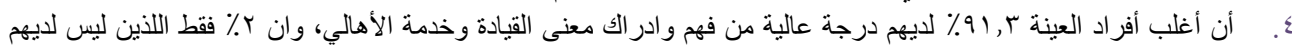
ادر الك بمعنى القيادة.

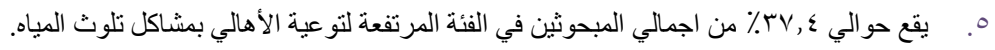

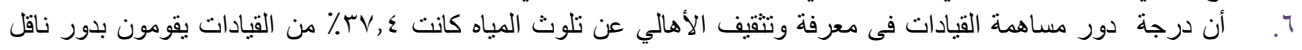

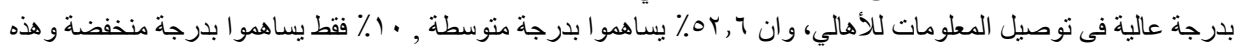
نتيجة مرضية. 


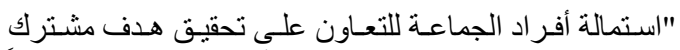

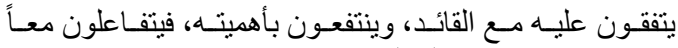

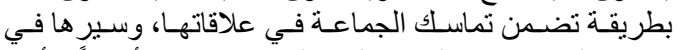

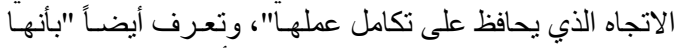

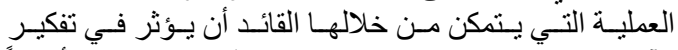

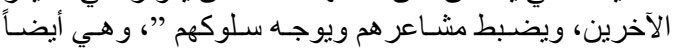

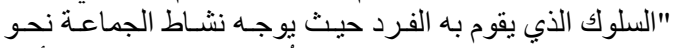

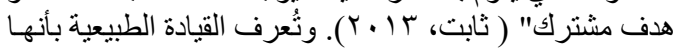

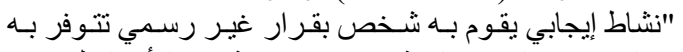

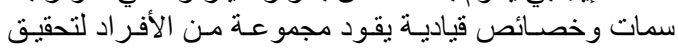

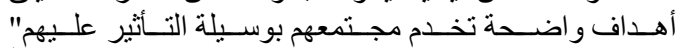
(Mcentire and Greene-Shortridge, 2011) لأهمية الدور العـام الـي يلعبـه القادة في التـأثير علـي أفكـار

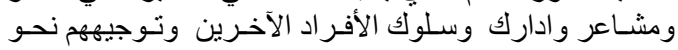

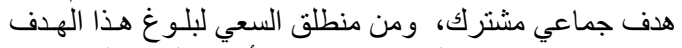

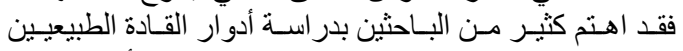

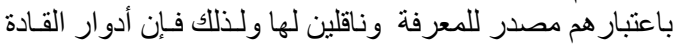

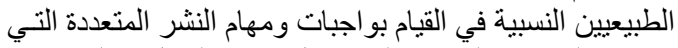

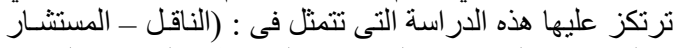

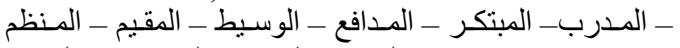

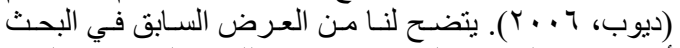

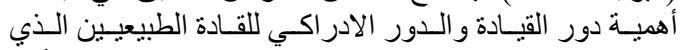

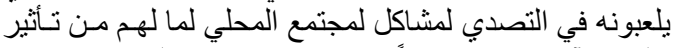

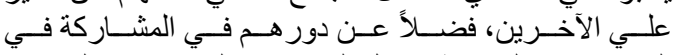

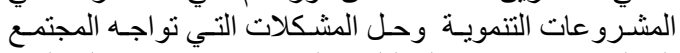

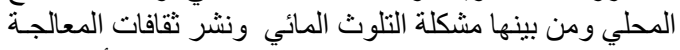

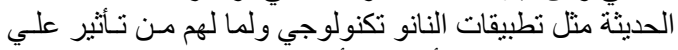

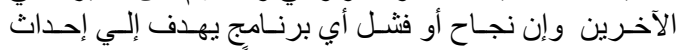

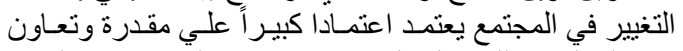

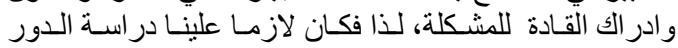

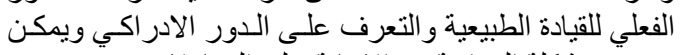

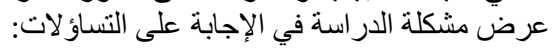

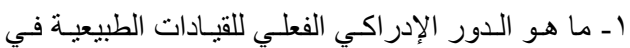

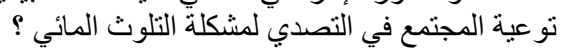

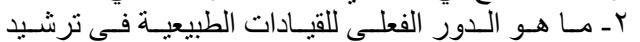
استهلاك مياه الشرب؟ هـورب الدور

\section{أهداف البحث}

للإجابة على التساؤلات السابقة يمكن صياغة أهداف البحث التالية:

$$
\begin{aligned}
& \text { ا. التعرف على خصائص المبحوثين ومستوى }
\end{aligned}
$$

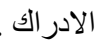

$$
\begin{aligned}
& \text { Y. التعرف على معنوية الفروق بين المتغيرات } \\
& \text { الشخصية والدور الإدر اكي للقادة الطبيعبين. }
\end{aligned}
$$

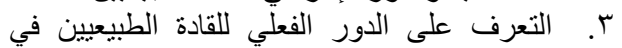

$$
\begin{aligned}
& \text { التو عية بمشاكل المياه. }
\end{aligned}
$$

\section{المقدمة}

عرفت القيـادة بأنهـا القدرة على التـأثير بـالآخرين وتوجيـه

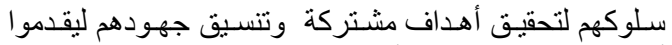

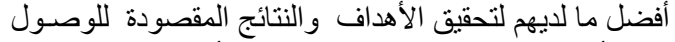

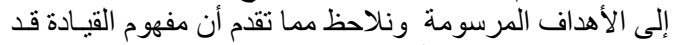

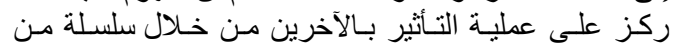

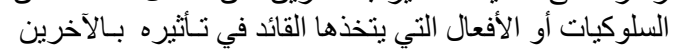

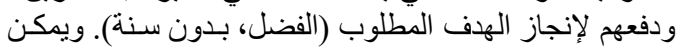

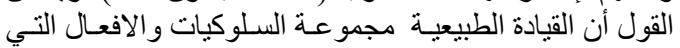

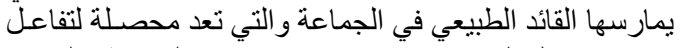

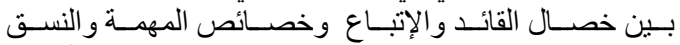

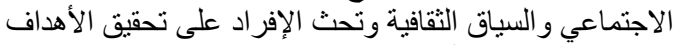

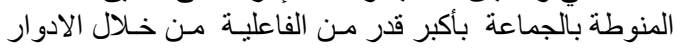

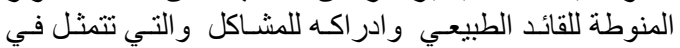

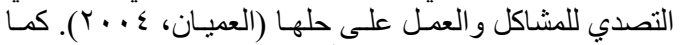

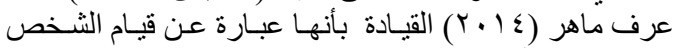

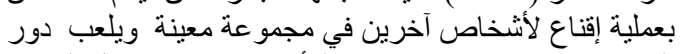

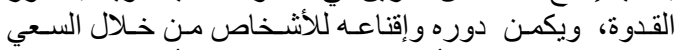

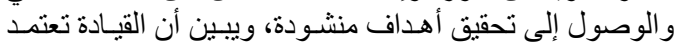

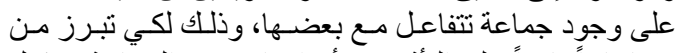

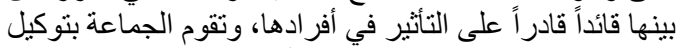

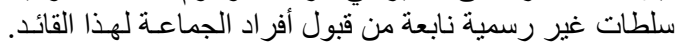

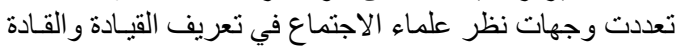

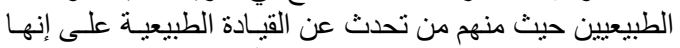

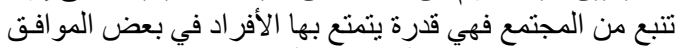

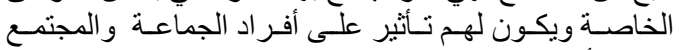

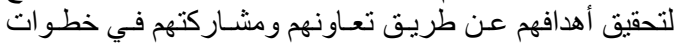

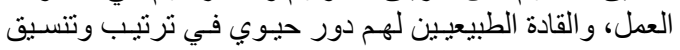

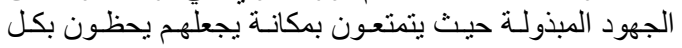

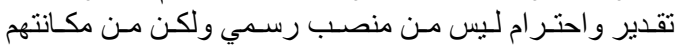

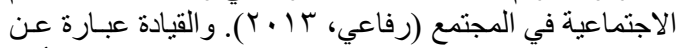

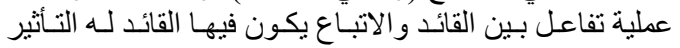

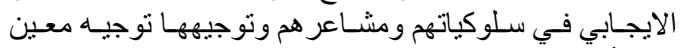

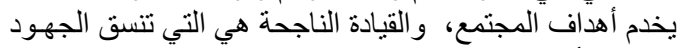

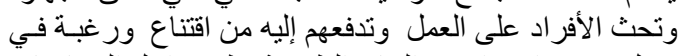

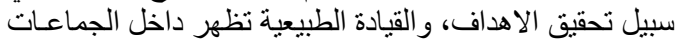

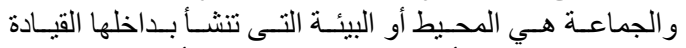

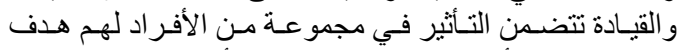

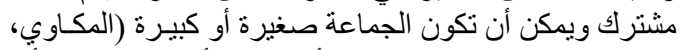

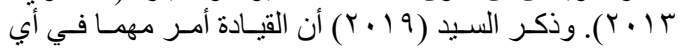

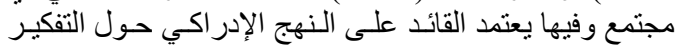

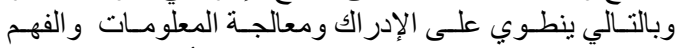

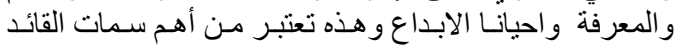

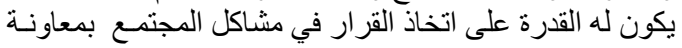

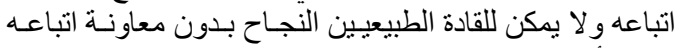

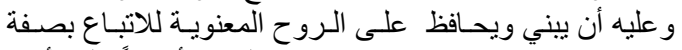

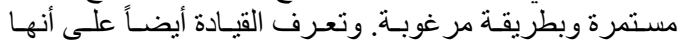


ومشاكلها. وقد تم قياس هذا المتغير من خلال المحاور

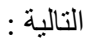
درجة المساهمة فى التو عية بترشيد الاستهلاك: ويقصد

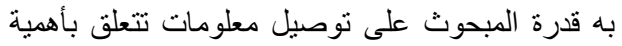

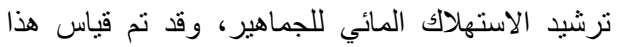

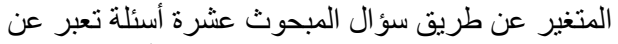

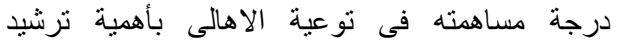

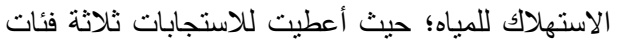

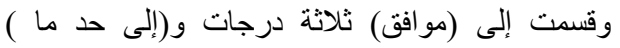

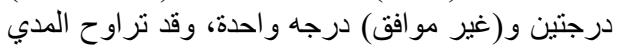

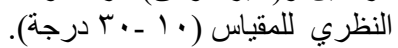

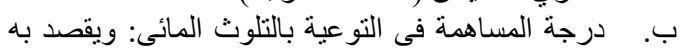

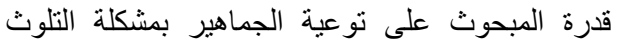

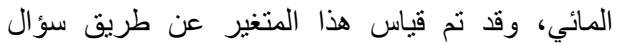

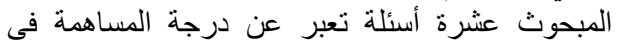

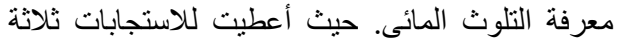

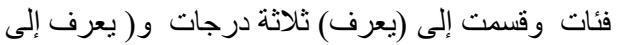

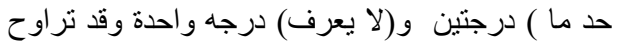

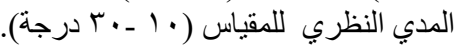

\section{فروض البحث}

م الفرض البحثي الأول: توجد علاقة معنوية بين

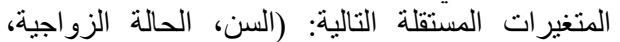

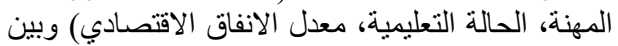
الدور الادر اكي للقادة الطبيعين في المساهدة في ترشيد

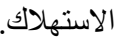

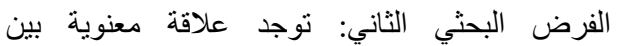
المتغيرات المستقلة التالية : (السن، الحالة الزئلة الزواجية،

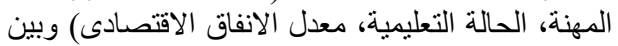
الدور الادر اكي للقادة الطبيعين في المساهمة في توعية الأنية

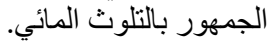

\section{النتائج ومناقشتها}

\section{أولا: النتائج المتعلقة بالخصائص الثخصية للمبحوثين}

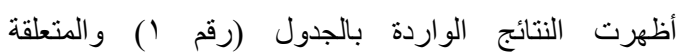
بالخصائص الشخصية للمبحوثين ما يلي:

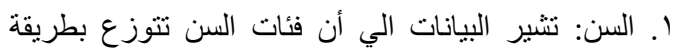

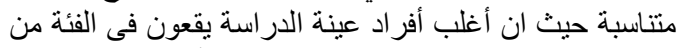

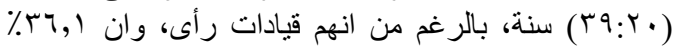

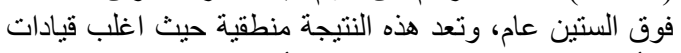

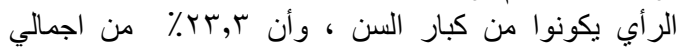

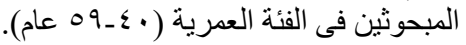

\section{الطريقة البحثية}

استخدمت الدراسة المنهج الوصفي التحليلي بألاضافة الي الكياتي

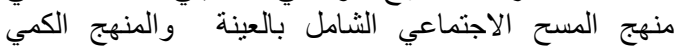

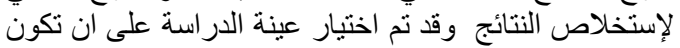

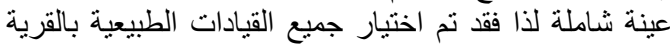

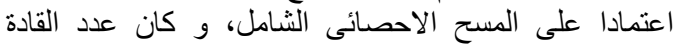

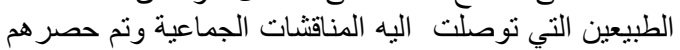

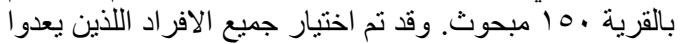

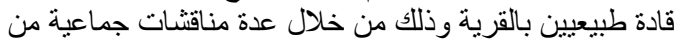

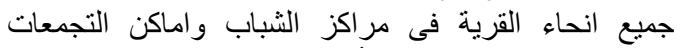

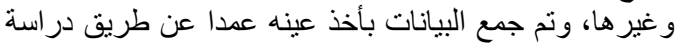

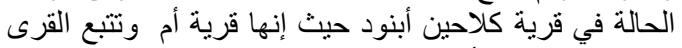

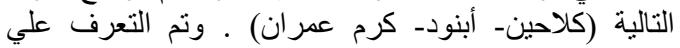

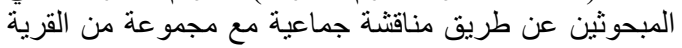

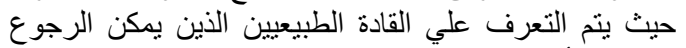

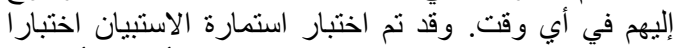

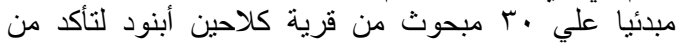

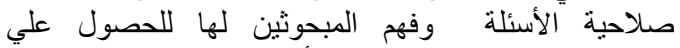

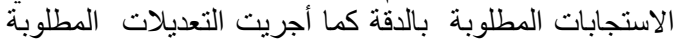

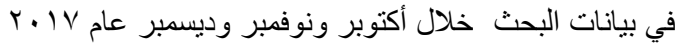

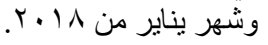

\section{المتغير ات البحثية وطرق قياسها}

1. السن: ويقصد به العمر الحالي للمبحوث مقاسا بعدد

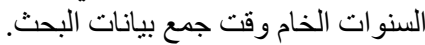

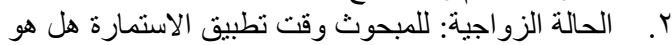

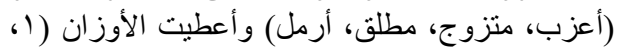

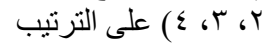

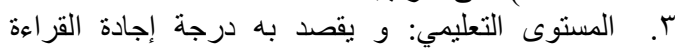

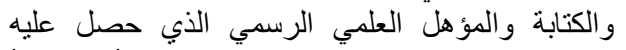

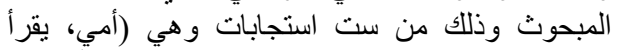

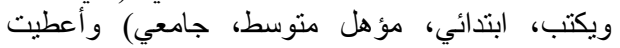

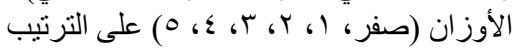

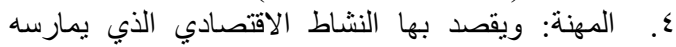

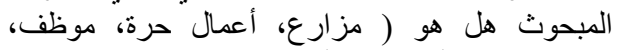

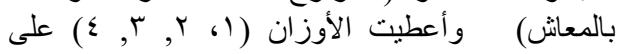

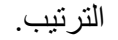

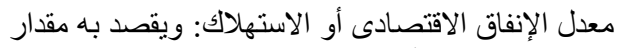

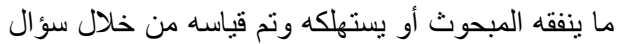
المبحوث ثلاثة أسئلة تتضمن (مايكفي لثراء من ملابس

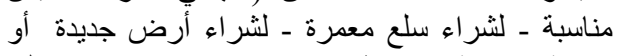

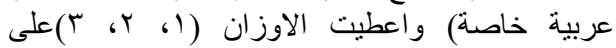

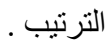
7. الدور الادر اكى : ويقصد به ددى مساهمة المبحوث فى الهي توعية الجماهير بمفاهيم التطبيقات الحديثة وأهمية المياه 


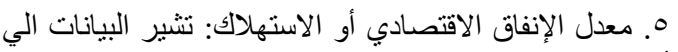

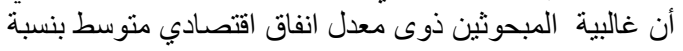

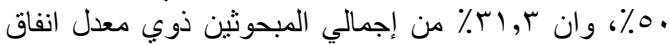

مرتفع.

ثانيا: النتائج المتعلقة بالدور الإدراكي للمبحوثين ا ـ درجة المساهمة فى توعية الجمهور بالتلوث المائي

أشارت البيانات الواردة بالجدول رقم (Y) أن درجة مساهمة

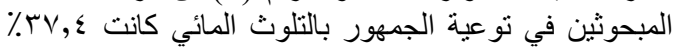

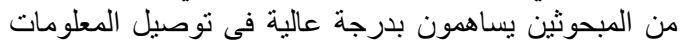

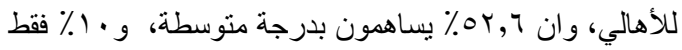

يساهمون بدرجة منخفضة وان وهذه نتيجة مرضية. r. الحالة الزواجية: نشير البيانات الي أن الغالبية العظمي من

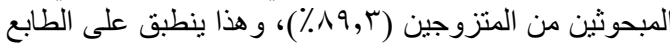

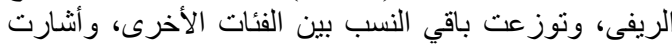

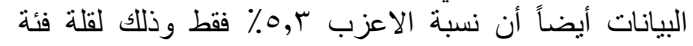
الثباب فى العينة.

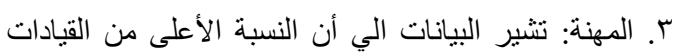

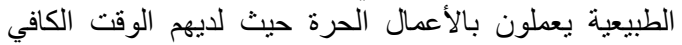

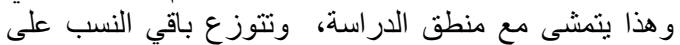

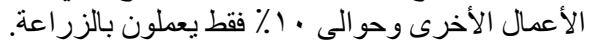

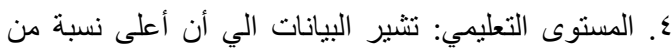

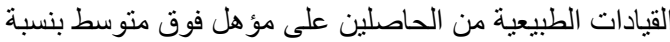

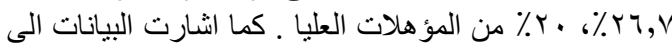

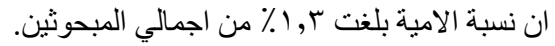

\begin{tabular}{|c|c|c|}
\hline$\%$ & عدد & الخصائص الثخصية \\
\hline \multicolumn{3}{|r|}{ (1) فئات السن: } \\
\hline$\varepsilon,, \uparrow$ & 71 & من (• (Y_Y) سنة \\
\hline$r r, r$ & ro & من(·ـ _09) سنه \\
\hline$r 4,1$ & $0 \leq$ & . . آ عام فأكثر \\
\hline \multicolumn{3}{|r|}{ (ץ) الحالة الزواجية: } \\
\hline $0, r$ & $\Lambda$ & أعزب \\
\hline$\Lambda 9, r$ & $1 T \leq$ & منزوج \\
\hline$\varepsilon$ & 7 & مطلق \\
\hline $1, \varepsilon$ & $r$ & أرمل \\
\hline \multicolumn{3}{|r|}{ (T) المهنة: } \\
\hline $1 \cdot, \mathrm{V}$ & 17 & مزارع \\
\hline$\varepsilon 0, r$ & 71 & أعمال حرة \\
\hline$\varepsilon$ & 7. & موظف \\
\hline$\varepsilon$ & 7 & بالمعاش \\
\hline \multicolumn{3}{|r|}{ (ع ( المستوى التعليمي: } \\
\hline $1, \Gamma$ & $r$ & أمي - - مي \\
\hline $1 r, r$ & $r \cdot$ & يقر أ ويكتب \\
\hline $1 \wedge, V$ & rA & اعدادي \\
\hline$r$. & $r \cdot$ & متوسط \\
\hline$r \uparrow, V$ & $\varepsilon$. & فوق منوسط \\
\hline$r \cdot$ & $r \cdot$ & عالي \\
\hline \multicolumn{3}{|r|}{ (0) معدل الانفاق الاقتصـادي: } \\
\hline$r, r$ & $\sum V$ & معدل انفاق عالي \\
\hline 0. & vo & معدل انفاق متو سط \\
\hline $1 \wedge, \vee$ & $r \wedge$ & معدل انفاق منخفض \\
\hline
\end{tabular}

جدول (r): توزيع أفراد العينة وفقا لدرجة المساهمة فى توعية الجمهور بالتلوث المائي (ن = م (10).

\begin{tabular}{|c|c|c|}
\hline$\%$ & 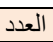 & درجة المساهمة فى معرفة التلوث \\
\hline$r V, \varepsilon$ & 07 & درجة عالية (·r - ع T) \\
\hline Or, 1 & 199 & درجة متوسطة (IV_rT) \\
\hline 1 . & 10 & درجة منخفضة (7 ( - (1) \\
\hline $1 \ldots$ & 10. & المجموع الكلى \\
\hline
\end{tabular}

المصدر : عينة الدراسة. 


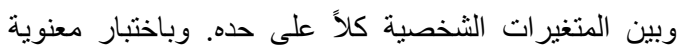

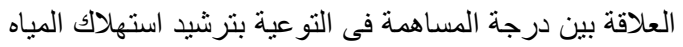

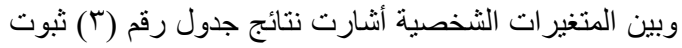

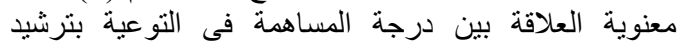

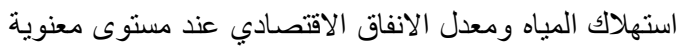

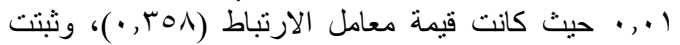

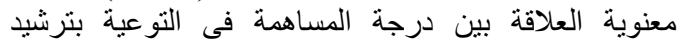

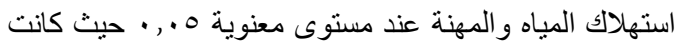

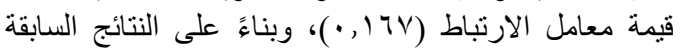

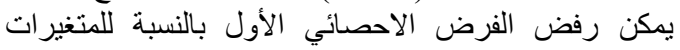

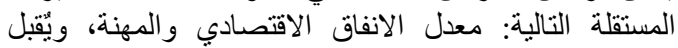

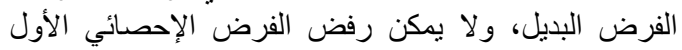
لباقي المتغير ات المستقلة المدروسة.
ثالثا: النتائج المتعلقة بالعلاقات الارتباطية بين المتغيرات المستقلة المدروسة والدور الإدراكي للمبحوثين بالين

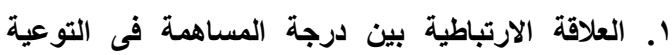
بترشيد استهلاك المياه وبين المتغيرات المستقلة المدروسة فئة المبلة

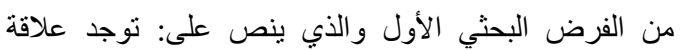

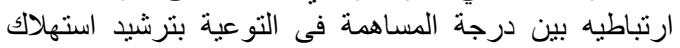

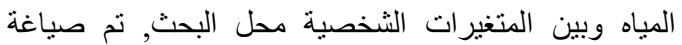

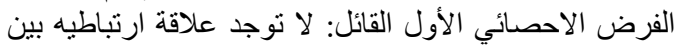

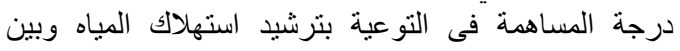

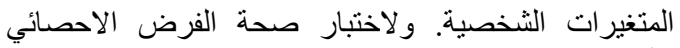

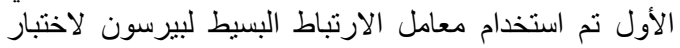
العلاقة بين درجة المساهمة في التوعية بترشيد استهلاك المياه

جدول (ए): نتائج العلاقة بين درجة المساهمة فى التوعية بترشيد استهلاك المباه وبين المتغيرات الثخصية.

\begin{tabular}{|c|c|}
\hline معامل الارتباط & المتغيرات الشخصية \\
\hline$\cdot, \ldots 7$ & السن \\
\hline$\cdot, \cdot 1$. & الحالة الزواجية \\
\hline$*,, 17 V$ & المهنة \\
\hline$\cdot, \cdot V Y$ & المستوى التعليمي \\
\hline$* * \cdot$, rON & معدل الانفاق الاقتصادي \\
\hline
\end{tabular}

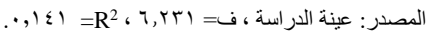

المساهمة فى التوعية بالتلوث المائي وبين المتغيرات

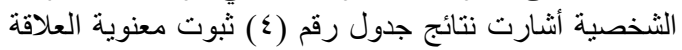

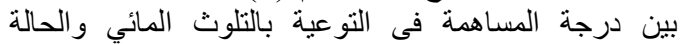

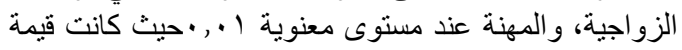

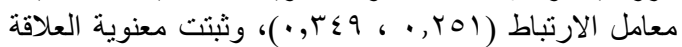

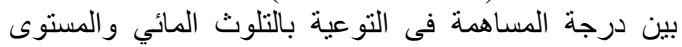

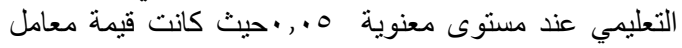

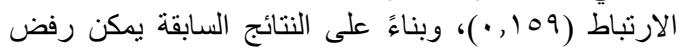
الفرض الاحصائي الثاني بالنسبة للمتغيرات ات المستقلة التبانة النالية:

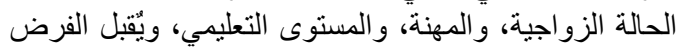

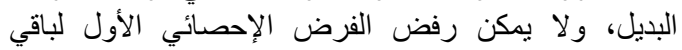
المتغير ات المستقلة المدروسة رفهي r. العلاقة الارتباطية بين درجة المساهمة في التوعية بالتلوث المائي وبين المتنغيرات المستقلة المدروسة في الماند

من الفرض البحثي الثاني والذي ينصة على: توجد علاقة ارتباطيه بين درجة المساهة في التنو عية بالتلوث المائي وبين

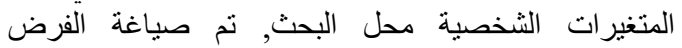
الاحصائي الثاني القائل: لا توجد علئ علافية ارتباطيه بين درجة

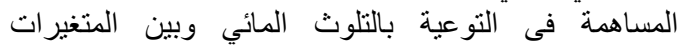

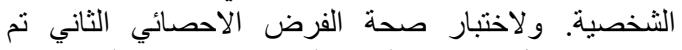
استخدام معامل الارتباط البسيط لبيرسون لاختبار العار العلاقة بين التين

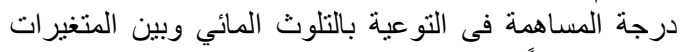

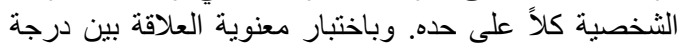

جدول (§) ): نتائج العلاقة بين درجة المساهمة فى التو عية بالتلوث المائي وبين المتغير ات الثخصية.

\begin{tabular}{|c|c|}
\hline معامل الارتباط & المتغير ات الثخصية \\
\hline$\cdot, \cdot \Lambda r$ & السن \\
\hline **, Y, YOI & الحالة الزو اجية \\
\hline$* *, r, r \leq q$ & المهنة \\
\hline$*, 109$ & المستوى التعليمي \\
\hline$\cdot, \cdot V V$ & معدل الانفاق الاقتصادي \\
\hline
\end{tabular}




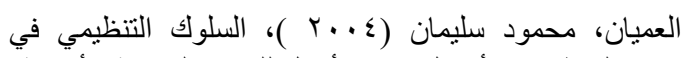

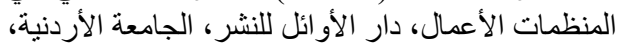

$$
\text { الأردن. }
$$

الفضل، مؤيد (بدون سنة)، نظريات اتخاذ القرار، الطبعة الطبة الأولى، دار المناهج، عمان، الأردن.

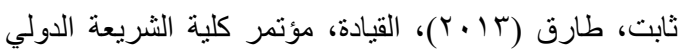
الر ابع، جامعة أم البو اقي، الجزائر.

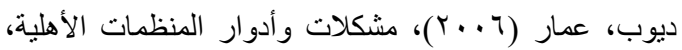

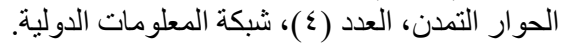

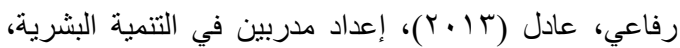

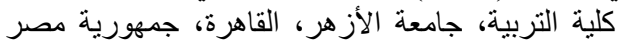

$$
\text { العربية. }
$$

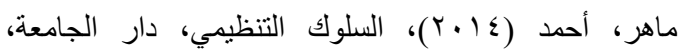
الاسكندرية، جمهورية مصر العربية.

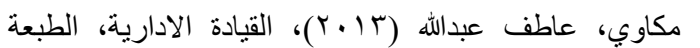
الاولى، مؤسسة طيبة للنشر و التوزيع، القاهرة، جمهورية الأنية

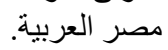

توصيات البحث

بناءً على ما توصل إليه البحث يمكن اقتراح مجموعة من

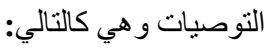
1. الاهتمام بمعرفة القادة الطبعيين في كل مجتمع.

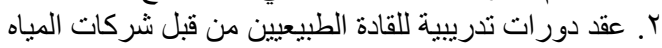

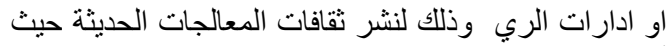

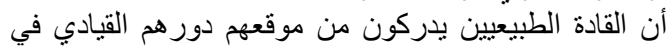

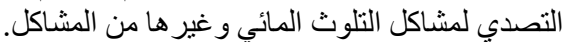

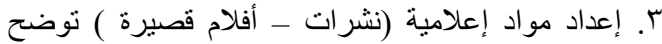

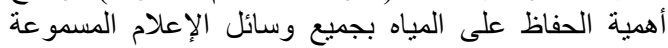
و المرئية و المقروءة.

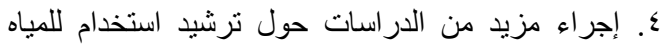
للكثف عن مزيد من الجوانب الاجتماعية والثقافية المرتبطة بها. قائمة المراجع مراجع باللغة العربية

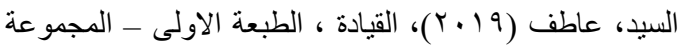

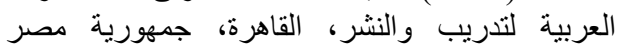
العربية.

\section{مراجع باللغة الانجليزية}

McEntire, L. E. and Greene-Shortridge, T. M. (2011), "Recruiting and selecting leaders for Innovation: How to find the right leader", Advances in Developing Human Resources, Vol. 13 No. 3, pp. 266- 278. 